\title{
The Turkish version of the Neck Bournemouth Questionnaire in patients with chronic neck pain: a cultural adaptation, reliability, and validity study
}

\author{
Emine Aslan Telci ${ }^{1}$, Ummuhan Bas Aslan ${ }^{1}$, Nesrin Yagci ${ }^{1}$, Ugur Cavlak², Elif Gur Kabul ${ }^{1}$, \\ Guzin Kara' ${ }^{1}$, Tugce Kose ${ }^{3}$, Feride Yarar ${ }^{1}$, Sevilay Karahan ${ }^{4}$, Orcin Telli Atalay ${ }^{1}$
}

${ }^{1}$ School of Physical Therapy, Pamukkale University, Denizli, Turkey
2Department of Physiotherapy and Rehabilitation, Avrasya University, Trabzon, Turkey
${ }^{3}$ Denizli State Hospital, Denizli, Turkey
${ }^{4}$ Faculty of Medicine, Department of Biostatistics, Hacettepe University, Ankara, Turkey

Submitted: 16 January 2018; Accepted: 28 March 2018;

Online publication: 23 October 2019

Arch Med Sci 2021; 17 (3): 708-713

DOI: https://doi.org/10.5114/aoms.2019.89322

Copyright @ 2019 Termedia \& Banach

\section{Abstract}

Introduction: The cultural adaptation of a self-report measurement in different languages is important for developing common strategies for evaluation and treatment. The Neck Bournemouth Questionnaire (NBQ), which was developed to evaluate patients with neck pain, was adapted from the Bournemouth Questionnaire in accordance with the International Classification of Functioning, Disability and Health (ICF) categories. The aim of this study was to conduct the Turkish cultural adaptation, validity and reliability study of the NBQ.

Material and methods: The study included 119 patients (93 females, 26 males; mean age: $37.2 \pm 11.8$ years) with chronic nonspecific neck pain. The NBQ, Neck Disability Index (NDI) and Nottingham Health Profile (NHP) questionnaires were administered to all the subjects. Test-retest reliability (intraclass correlation coefficient) and the internal consistency (Cronbach's $\alpha$ ) were the methods used for the reliability study. The relationship between NBQ, NDI and NHP was investigated for concurrent validity. Exploratory and confirmatory factor analysis was used for construct validity.

Results: The Neck Bournemouth Questionnaire showed good internal consistency $(\alpha=0.87)$. The test-retest reliability coefficient was $0.913(95 \% \mathrm{Cl}$ : $0.875-0.940)$. The correlations between NBQ and NDI and NHP were significant $(p<0.05)$. The questionnaire was found to have one factor and the explained variance was $59.084 \%$ as a result of factor analysis.

Conclusions: The Neck Bournemouth Questionnaire is a valid and reliable scale for patients with chronic neck pain in the Turkish population.

Key words: validity and reliability, pain, outcome measures.

\section{Introduction}

Neck pain is an important health problem that is very common in society. Lifetime prevalence has been reported to vary between $14.2 \%$ and $71 \%$ [1]. Symptoms recur within 1-5 years in $50-85 \%$ of the patients [2]. It was found to cause disability in $5 \%$ of the population in a study conducted in Canada [3]. Neck pain decreases the quality of life of the patients with the disability and the activity limitation it causes can also lead to economic and societal costs due to significant health care use and labor loss [4-6].

\section{Corresponding author:}

Emine Aslan Telci, Assoc. Prof. Pamukkale University School of Physical Therapy 20070, Denizli, Turkey Phone: $+90(258) 2964272$ Fax: +90(258)2964494 E-mail: easlantelci@ gmail.com 
Although the pain itself is the most important symptom that requires treatment in spinal pain, it is a multidimensional individual experience with sensory, affective, cognitive, and social aspects [7]. It is therefore more appropriate to consider a biopsychosocial model rather than a medical model when identifying the assessment and treatment approaches [4].

The sensitivity of the Functional Outcomes Questionnaire which has been developed specifically for the region is much greater than the general health scales $[7,8]$. Some pain and disability questionnaires were developed specifically for neck pain patients. Validity and reliability studies have been conducted in various languages including Turkish for the Neck Disability Index (NDI) $[8,9]$, the Neck Pain and Disability Scale (NPDS) $[10,11]$, the Northwick Park Neck Pain Questionnaire (NPQ) [12, 13] and the Copenhagen Neck Functional Disability Scale (CNFDS) [14] that have been developed for this purpose. In a systematic review published in 2010 the validity and reliability of the NDI, NPDS and the Neck Bournemouth Questionnaire (NBQ) were reported as excellent [15].

The Neck Bournemouth Questionnaire (NBQ), which was developed to evaluate patients with neck pain, was adapted from the Bournemouth Questionnaire in accordance with the International Classification of Functioning, Disability and Health (ICF) categories [5]. It includes 7 core items evaluating patients with neck pain based on a biopsychosocial approach. The NBQ was originally developed in English but studies have also been conducted on German, French, Italian, Dutch and Brazilian Portuguese language versions $[5,6$, 16-20]. The cultural adaptation of a self-report measurement in different languages is important for developing common strategies for evaluation and treatment [6]. The Turkish version study of this questionnaire, which is easy to implement and can be completed in a short duration, has not yet been conducted.

The aim of planning this study was to conduct the Turkish version of the Neck Bournemouth Questionnaire, which is a multi-dimensional pain assessment tool, in Turkish-speaking people with neck pain.

\section{Material and methods}

Permission was obtained via e-mail to conduct this study from the author who developed the original questionnaire [5]. The study was carried out at Denizli Servergazi State Hospital and Pamukkale University. Participants were diagnosed by a specialist doctor as having a nonspecific chronic neck pain problem. Informed consent was obtained from all participants included in the study. Approval for the study was also obtained from the Pamukkale University Non-Interventional Clinical Studies Ethics Committee (601167787020/54425).

One hundred and nineteen patients (93 females, 26 males; mean age: $37.2 \pm 11.8$ years) suffering from neck pain for at least 3 months were included in the study. The inclusion criteria were: (1) aged 18-65 years, (2) a minimum of 5 points from the Neck Disability Index, (3) able to speak and read Turkish fluently. The exclusion criteria were: (1) patients who underwent spinal surgery, (2) specific neck pain such as a malignancy, fracture or systemic rheumatoid disorder, (3) systemic diseases, (4) pregnancy, (5) subjects who cannot answer the questionnaires due to inability to understand and/or answer, (6) subjects receiving treatment such as physiotherapy or drugs at the time of the study.

\section{Questionnaires}

\section{The Neck Bournemouth Questionnaire}

Based on the biopsychosocial disease model, the questionnaire consists of a total of 7 questions: (1) pain intensity; (2) disability in activities of daily living; (3) disability in social activities; (4) anxiety; (5) depression; (6) fear avoidance behavior and (7) pain locus of control. Each question consists of an 11-point numerical rating scale. The total score from the questionnaire ranges between 0 and $70[5,6,18]$. Increase in the score indicates worsening of the patient's condition.

\section{Neck Disability Index}

The scale consists of ten sections in total (pain intensity, personal care, lifting, reading, headaches, concentration, work, driving, sleeping, and recreation). The total score varies from 0 (no disability) to 50 (total disability) $[8,9]$.

\section{Nottingham Health Profile}

The Nottingham Health Profile (NHP) is a general health condition scale that evaluates the problems perceived by the patient in 6 different aspects (physical mobility, pain, sleep, emotional reactions, social isolation, and energy level). The maximum score in each section is 100 and the total score of the questionnaire is between 0 and 600 [21, 22].

\section{Translation}

Guidelines developed by Beaton et al. were used for the translation and cross-cultural adaptation process [23]. For forward translation two different people whose native language is Turkish and who speak English at a very good level translated the questionnaire in English into Turkish ( $\mathrm{T} 1$ and T2). One of the translators was a physiother- 
apist and was aware of the purpose of the study. This was to ensure the equivalence from a clinical perspective, instead of a literal equivalence. The other translator was an English teacher and was a blinded for the purpose of the study. This made it possible to reflect the language used by the population and to emphasize equivocal meanings in the original questionnaire. Later, translations by two translators were synthesized into a single global translation (T12). In the back translation stage, the synthesized T12 translation was translated into English again by two people who were not informed about the purpose of study, whose native language is English and who speak Turkish at a good level (BT1 and BT2). To achieve cross-cultural equivalence, an expert committee consisting of four translators and three physiotherapists came together to form the prefinal state of the questionnaire for field testing. For the prefinal test, 33 patients with neck pain were asked to indicate the expressions they were unable to understand for each item during the questionnaire

Table I. Matching of the subscales between the NBQ, NHP and NDI

\begin{tabular}{|lcc|}
\hline NBQ subscale & NHP subscale & NDI subscale \\
\hline Pain intensity & Pain & Pain intensity \\
\hline $\begin{array}{l}\text { Physical } \\
\text { function }\end{array}$ & Physical activity & $\begin{array}{c}\text { Personal care } \\
\text { Lifting } \\
\text { Reading } \\
\text { Driving }\end{array}$ \\
& & Recreation \\
\hline Social function & Social isolation & Recreation \\
\hline Anxiety & $\begin{array}{c}\text { Emotional } \\
\text { reaction } \\
\text { Energy level }\end{array}$ & \\
\hline $\begin{array}{l}\text { Depression } \\
\text { Emotional } \\
\text { reaction } \\
\text { Eain locus of }\end{array}$ & Pain & \\
\hline Control & & \\
\hline PBQ - Neck Bournemouth Questionnaire, NHP-Nottingham Health
\end{tabular}

Profile, NDI - Neck Disability Index.

Table II. Demographic and clinical characteristics of patients $(n=119)$

\begin{tabular}{|c|c|c|}
\hline Parameter & Mean \pm SD & Min.-max. \\
\hline Age [years] & $37.2 \pm 11.8$ & $20-65$ \\
\hline $\mathrm{BMI}\left[\mathrm{kg} / \mathrm{cm}^{2}\right]$ & $25.9 \pm 5.2$ & $16.6-44.1$ \\
\hline Pain duration [months] & $23.3 \pm 24.6$ & $3-84$ \\
\hline VAS $[\mathrm{cm}]$ & $5.4 \pm 1.8$ & $1-9$ \\
\hline
\end{tabular}

response. The final version of the NBQ was created by the committee considering the feedback from the patients and the validity and reliability study was started.

\section{Statistical analysis}

The data were analyzed with the SPSS software, version 21.0. Continuous variables were presented as mean \pm standard deviation and categorical variables as number (percentage).

\section{Reliability}

Test-retest reliability and internal consistency analyses were done to determine the reliability of the questionnaire. In the test-retest reliability analysis the intraclass correlation coefficient (ICC) (95\% confidence interval) and Spearman correlation coefficient were used. ICC values range from 0.00 to 1.00 . Above 0.80 shows excellent reliability and $0.60-0.80$ means good reliability $[8,24]$. NBQ was administered to the same patients again 7 days later for the test-retest reliability. For determining the internal consistency Cronbach's $\alpha$ coefficient was used. Item total correlation and item-deleted Cronbach's $\alpha$ coefficient were calculated during this analysis. If this value is above 0.80 , it indicates excellent reliability [25].

\section{Validity}

For the construct validity exploratory and confirmatory factor analyses were applied. Prior to the exploratory factor analysis, the adequacy of the sample was determined by the Kaiser-MeyerOlkin test and Bartlett's test of sphericity was used for the suitability. Whether NBQ was unidimensional as in the original structure was shown with the help of various conformity indexes during confirmatory factor analysis. For concurrent validity the correlation coefficient between NBQ, NDI and NHP was examined. Table I shows the matching of the various subscales on the NHP and NDI questionnaires with the seven subscales on the NBQ. The relationship was evaluated with Spearman correlation analysis [26].

\section{Results}

The mean duration of pain and pain intensity were $23.3 \pm 24.6$ months and $5.4 \pm 1.8 \mathrm{~cm}$ respectively for a total of 119 patients. Demographic and clinical data of the patients are presented in Table II.

\section{Reliability}

The test-retest reliability coefficient was 0.913 (ICC 95\% Cl: 0.875-0.940). ICC values for each question ranged from 0.807 to 0.888 . The results of our study and the correlation coefficients are presented in Table III. 
The Cronbach's $\alpha$ value of the scale was 0.87 . This result means that the internal consistency of the scale was excellent. In Table IV it is shown that the Cronbach's $\alpha$ value decreased when each question was deleted.

\section{Construct validity}

The results were 0.846 for the Kaiser-MeyerOlkin test and for Bartlett's test of sphericity $p<0.001$. The questionnaire was found to have one factor and the explained variance was $59.084 \%$ as a result of factor analysis (cmin/df: 1.661, GFI: 0.952, AGFI: 0.887, RMSEA: 0.075, $\chi^{2}$ : $19.936, p=0.068)$. Factor loading values were between 0.63 and 0.845 . Item 7 had the lowest factor loading value.

\section{Concurrent validity}

Concurrent validity results showed a correlation between NBQ total score and NDI total score $(r=0.318)$ and also between NBQ total score and NHP total score $(r=0.581)$. When the relationship between the subscales of NBQ, NDI and NHP and the total scale scores was analyzed, NBQ was found to show correlation values between 0.206 and 0.597 with these scales (Table V).

\section{Discussion}

The aim of this study was to conduct the Turkish cultural adaptation, validity and reliability study of the Neck Bournemouth Questionnaire in patients with chronic neck pain. Our results showed that the questionnaire is a valid and reliable measurement method in Turkish speaking patients with chronic neck pain.

The ICF is a standard framework approved by the World Health Organization (WHO) that measures health and disability at the individual and population level $[15,19,27]$. The positive and negative aspects of functioning from a biological, personal and social point of view are expressed with the terms functioning and disability. Performing version studies of ICF-based self-report measurements that provide a general language for disability in different cultures will be helpful in the evaluation of musculoskeletal pain and in the generation of common solutions for interpretation of treatment outcomes [27].

Ferreira et al. reported that NBQ, NDI and NPDS have demonstrated a well-balanced distribution of items across the ICF components [15]. Therefore, it is important to present the Turkish version of the NBQ in the literature for using it in clinical practice and research. For the questionnaire validation studies, it is recommended to select the questionnaires which are validated, considered to be the gold standard and context specific if possi-
Table III. Test-retest correlation coefficient values of Neck Bournemouth Questionnaire (NBQ)

\begin{tabular}{|c|c|c|}
\hline NBQ & ICC $(95 \% \mathrm{CI})$ & $r$ \\
\hline Total & $0.913(0.875-0.940)^{\star \star}$ & $0.847^{\star *}$ \\
\hline Item 1 & $0.854(0.791-0.899)^{\star *}$ & $0.772^{* *}$ \\
\hline Item 2 & $0.888(0.839-0.922)^{\star *}$ & $0.820^{\star *}$ \\
\hline Item 3 & $0.858(0.796-0.901)^{\star *}$ & $0.770^{\star *}$ \\
\hline Item 4 & $0.868(0.810-0.908)^{\star *}$ & $0.779^{\star *}$ \\
\hline Item 5 & $0.853(0.789-0.898)^{\star \star}$ & $0.752^{\star *}$ \\
\hline Item 6 & $0.828(0.753-0.880)^{\star *}$ & $0.725^{\star *}$ \\
\hline Item 7 & $0.807(0.723-0.866)^{\star *}$ & $0.678^{\star *}$ \\
\hline
\end{tabular}

ICC - intraclass correlation coefficient. All other correlations are significant at ${ }^{* *} p<0.001, r-$ Spearman corelation coefficient.

Table IV. Internal consistency of the Turkish version of the Neck Bournemouth Questionnaire (NBQ)

\begin{tabular}{|lc|}
\hline $\begin{array}{l}\text { NBQ } \\
\text { item }\end{array}$ & Cronbach's $\alpha$ if item deleted \\
\hline Item 1 & 0.863 \\
\hline Item 2 & 0.854 \\
\hline Item 3 & 0.850 \\
\hline Item 4 & 0.850 \\
\hline Item 5 & 0.874 \\
\hline Item 6 & 0.846 \\
\hline Item 7 & 0.877 \\
\hline
\end{tabular}

Table V. External longitudinal construct validity of items of the Neck Bournemouth Questionnaire (NBQ)

\begin{tabular}{|c|c|c|}
\hline NBQ item & Counterpart measure & $r$ \\
\hline \multirow[t]{2}{*}{1} & NDI Pain intensity & $0.557^{* *}$ \\
\hline & NHP Pain & $0.461^{* *}$ \\
\hline \multirow[t]{6}{*}{2} & NDI Personal care & $0.430^{* *}$ \\
\hline & NDI Lifting & $0.361^{\star *}$ \\
\hline & NDI Reading & $0.397^{\star *}$ \\
\hline & NDI Driving & $0.329^{* *}$ \\
\hline & NDI Recreation & $0.389^{* *}$ \\
\hline & NHP Physical activity & $0.313^{* *}$ \\
\hline \multirow[t]{2}{*}{3} & NDI Recreation & $0.429^{* *}$ \\
\hline & NHP Social isolation & $0.206^{*}$ \\
\hline \multirow[t]{2}{*}{4} & NHP Emotional reaction & $0.479^{* *}$ \\
\hline & Energy level & $0.400^{* *}$ \\
\hline \multirow[t]{2}{*}{5} & NHP Emotional reaction & $0.597^{\star *}$ \\
\hline & Energy level & $0.424^{* *}$ \\
\hline 6 & NDI Work & $0.380^{* *}$ \\
\hline \multirow[t]{2}{*}{7} & NDI Pain intensity & $0.223^{*}$ \\
\hline & NHP Pain & $0.454^{* * *}$ \\
\hline \multirow[t]{2}{*}{ Total } & NDI Total & $0.318^{* \star}$ \\
\hline & NHP Total & $0.581^{* *}$ \\
\hline
\end{tabular}

$r$-Spearman correlation coefficient, ${ }^{*}$ correlation is significant at 0.05 level, ${ }^{* *}$ correlation is significant at 0.01 level, ${ }^{* * *}$ correlation is significant at 0.001 level. 
ble [25]. Therefore, one of the questionnaires that we chose in the validation study of the NBQ was the NDI, in which the Turkish validity and reliability study was conducted [24]. The other questionnaire was the NHP, which was in conformity with the subparameters of the NBQ and a validity and reliability study had been done in Turkish [22].

There are two types of reliability: internal consistency and test-retest reliability. Test-retest reliability measures over-time stability of measurements made at two different times [28]. In this analysis, it is recommended that an amount of time should pass for the patients to forget the answers in the initial assessment. However in this period of time, not having a change in the current status of patients associated with the disease is important [25]. Marx et al. [29] reported no difference between test and retest at an interval between 2 days and 2 weeks. It was seen that in the literature, different time intervals are preferred for the application of retest of the NBQ; and in some studies the time interval is not even specified. The test-retest time interval appears to be $2 \mathrm{~h}$ (hours) in the German version, $24 \mathrm{~h}$ in the French version and $1 \mathrm{~h}$ in the Brazilian Portuguese version [17, 18, 20]. It was determined that the original NBQ developed by Bolton and Humphreys had an ICC total score of 0.65 and that it changed between 0.50 and 0.63 for each questionnaire [5]. In the German version of the study it was reported that the total ICC value was 0.99 and it varied between 0.91 and 0.98 for seven questions [17]. In the Dutch version, it was determined that the ICC value varied between 0.83 and 0.99 for each question [19]. In the French version of the study, the total ICC value of the questionnaire was found to be 0.97 [18]. The test-retest reliability value of the Turkish NBQ with a week interval was determined as 0.913 for the total score, ranging from 0.807 to 0.913 for each question. According to the results of this study, the test-retest reliability of the Turkish version of the questionnaire showed stability over time.

The Cronbach's $\alpha$ value is widely used for internal consistency reliability analysis of questionnaires in different language versions [28]. In the study of Bolton and Humphreys, developers of the NBQ, they found Cronbach's $\alpha$ values of the survey to be $0.87,0.91$ and 0.92 , respectively in pre-treatment, retest and post-treatment administration [5]. Pre- and post-treatment Cronbach's $\alpha$ values in the German version were 0.79 and 0.80 [17], respectively, whereas it was found to be 0.98 in the Brazilian Portuguese version [20]. In the Turkish version study of the NBQ, we found that the Cronbach's $\alpha$ value was 0.87 , similarly to literature. This result shows that the Turkish version of the questionnaire is reliable.

According to the Kaiser-Meyer-Olkin and Bartlett's tests, the Turkish version of the NBQ has a one-factor questionnaire. Before our study, in the Italian version of the NBQ, the questionnaire was found to be two-factor [6]. Similarly to our results for the Turkish version of the questionnaire for back pain it was found to be one-factor [25]. The authors commented that even though it addresses multiple situations, the Bournemouth Questionnaire may be one-factor because of the small number of questions.

The concurrent validity analysis results showed the NBQ to be correlated with NDI and NHP total scores and items in chronic neck pain. The two lowest correlations were between NBQ/ third question- NHP/social isolation and NBQ/ seventh question-NDI/first question. The third question of the NBQ concerned social activity participation associated with neck pain, whereas the social isolation part of the NHP was not associated with pain. This difference may be the reason for the low correlation. Synchronizing the pain locus of control, the seventh question of the NBQ, with the subordinate items of NDI and NHP, is actually very difficult. Despite this, we wanted to analyze the correlations between this item and the pain-related part of the other two questionnaires. In the German version, the correlation between pain locus of control and NPDS pain control was also found to be low. The authors stated that it is impossible to make a match between NBQ/pain locus of control and NDI [17]. Similarly to our results, also in the validity studies of the NBQ in other languages, it was found that there was a correlation at varying levels [6, 20].

In conclusion, the studies among adult populations show that the prevalence of chronic pain is higher in all countries [30]. Musculoskeletal system pain is being studied in a wide range from non-specific pain to pain as a result of an underlying pathological condition such as chronic renal failure [31]. It is known that chronic neck pain, which is very common, affects the quality of life of the patient negatively in physical, social and psychological aspects [5]. Therefore, multidimensional analysis and determination of the factors that cause chronic neck pain are very important for taking the necessary preventive measures and determining appropriate treatment strategies. Translation of the self-report measures with proven validity and reliability to different languages is very important in terms of seeking common solutions in pain related problems.

The Neck Bournemouth Questionnaire evaluates chronic neck pain as multidimensional, can be completed in a short duration in the clinical setting and is easily understood by the patients. In conclusion, this study showed that the Turkish version of the NBQ is a valid and reliable measurement method. 


\section{Acknowledgments}

The authors thank Jennifer E. Bolton for her permission to translate the NBQ into Turkish, and the members of the committee (Hazel Lomax Yuceturk and Yasmin Jean Sheila Karaca) for their co-operation.

\section{Conflict of interest}

The authors declare no conflict of interest.

\section{References}

1. Fejer R, Kyvik KO, Hartvigsen J. The prevalence of neck pain in the world population: a systematic critical review of the literature. Eur Spine J 2006; 15: 834-48.

2. Carroll LJ, Hogg-Johnson S, van der Velde, et al. Course and prognostic factors for neck pain in the general population: results of the Bone and Joint Decade 20002010 Task Force on Neck Pain and Its Associated Disorders. Spine (Phila Pa 1976) 2008; 33 Suppl 4: S75-82.

3. Côté P, Cassidy D, Carroll L. The factors associated with neck pain and its related disability in the Saskatchewan population. Spine (Phila Pa 1976) 2000; 25: 1109-17.

4. Gross AR, Kaplan F, Huang S, et al. Psychological care, patient education, orthotics, ergonomics and prevention strategies for neck pain: an systematic overview update as part of the ICON project. Open Orthop J 2013 7: $530-61$.

5. Bolton JE, Humphreys BK. The Bournemouth Questionnaire: a short-form comprehensive outcome measure. II. Psychometric properties in neck pain patients. J Manip Physiol Ther 2002; 25: 141-8.

6. Geri T, Signori A, Gianola, et al. Cross-cultural adaptation and validation of the Neck Bournemouth Questionnaire in the Italian population. Qual Life Res 2015; 24: 735-45.

7. Blum-Fowler C, Peterson C, McChurch JF, Le Clech Y, Humphreys BK. Translation and validation of the German version of the Bournemouth questionnaire for low back pain. Chiropr Man Therap 2013; 21: 32.

8. Telci EA, Karaduman A, Yakut Y, Aras B, Simsek IE, Yagli N. The cultural adaptation, reliability, and validity of Neck Disability Index in patients with neck pain: a Turkish version study. Spine (Phila Pa 1976) 2009; 34: 1732-5.

9. Vernon H, Mior S. The Neck Disability Index: a study of reliability and validity. J Manip Physiol Ther 1991; 14 : 409-15.

10. Wheeler AH, Goolkasian P, Baird AC, Darden BV 2nd. Development of the neck pain and disability scale. Spine (Phila Pa 1976) 1999; 24: 1290-4.

11. Bicer A, Yazıcı A, Camdeviren H, Erdogan C. Assessment of pain and disability in patients with chronic neck pain: reliability and construct validity of the Turkish version of The Neck Pain And Disability Scale. Disabil Rehabil 2004; 26: 959-62.

12. Leak AM, Cooper J, Dyer S, Williams KA, Turner-Stokes L, Frank AO. The Northwick Park Neck Disability Questionnaire, devised to measure neck pain and disability. $\mathrm{Br}$ J Rheumatol 1994; 33: 469-74.

13. Kose G, Hepguler S, Atamaz F, Oder G. Comparison of four disability scales for Turkish patients with neck pain. J Rehabil Med 2007; 39: 358-62.

14. Jordan A, Manniche C, Mosdal C, Hindsberger C. The Copenhagen Neck Functional Disability Scale: a study of reliability and validity. J Manip Physiol Ther 1998; 21: 520-7.

15. Ferreira ML, Borges BM, Rezende IL, et al. Are neck pain and questionnaires compatible with the international classification of functioning, disability and health? A systematic review. Disabil Rehabil 2010; 32: 1539-46. 16. Bolton JE, Breen AC. The Bournemouth Questionnaire: a short-form comprehensive outcome measure. I. Psychometric properties in back pain patients. J Manip Physiol Ther 1999; 22: 503-10.

17. Soklic M, Peterson C, Humphreys BK. Translation and validation of the German version of the Bournemouth Questionnaire for Neck Pain. Chiropr Man Ther 2012; 20: 2 .

18. Martel J, Dugas C, Lafond D, Descarreaux M. Validation of the French version of the Bournemouth Questionnaire. J Can Chiropr Assoc 2009; 53: 102-20.

19. Schmitt MA, Schröder CD, Stenneberg MS, et al. Content validity of the Dutch version of the Neck Bournemouth Questionnaire. Man Ther 2013; 18: 386-9.

20. Kamonseki DH, Cedin L, Tavares-Preto J, Peixoto BO, Rostelato-Ferreira S. Translation and validation of Neck Bournemouth Questionnaire to Brazilian Portuguese. Rev Bras Reumatol 2017; 57: 141-8.

21. Hunt SM, McKenna SP, McEwen J, Backett EM, Williams J, Papp E. A quantitative approach to perceived health status: a validation study. J Epidemiol Community Health 1980; 34: 281-6.

22. Kucukdeveci AA, Mckenna SP, Kutlay S, Gursel Y, Whalley D, Arasıl T. The development and psychometric assessment of the Turkish version of Nottingham health profile. Int J Rehabil 2000; 23: 31-8.

23. Beaton DE, Bombardier C, Guillemin F, Ferraz MB. Guidelines for the process of cross-cultural adaptation of self-report measures. Spine (Philo Pa 1976) 2000; 25 : 3186-91.

24. Portney LG, Watkins MP. Foundation of Clinical Research: Applications to Practice. Appleton \& Lange, Norwalk, CT, 1993.

25. Gunaydin G, Citaker S, Meray J, Cobanoglu G, Gunaydin OE, Hazar Kanik Z. Reliability, validty, and cross-cultural adaptation of the Turkish version of the Bournemouth Questionnaire. Spine 2016; 41: E1292-7.

26. Bland JM, Altman DG. Statistical methods for assessing agreement between two methods of clinical measurement. Lancet 1986; 1: 307-10.

27. World Health Organization. The International Classification of Functioning, Disability and Health (ICF). 2001; Available from: http://www.who.int/classifications/ drafticfpracticalmanual2.pdf?ua=1 (January 2017).

28. Bek N, Simsek IE, Erel S, Yakut Y, Uygur F. Turkish version of impact family scale: a study of reliability and validity. Health Qual Life Outcomes 2009; 7: 4.

29. Marx RG, Menezes A, Horovitz L, Jones EC, Warren RF. A comparison of two time intervals for test-retest reliability of health status instruments. J Clin Epidemiol 2003; 56: 730-5.

30. Kozak-Szkopek E, Broczek K, Slusarczyk P, et al. Prevalence of chronic pain in the elderly Polish population results of the PolSenior study. Arch Med Sci 2017; 13: 1197-206.

31. Kusztal M, Trafidło E, Madziarska K, et al. Depressive symptoms but not chronic pain have an impact on the survival of patients undergoing maintenance hemodialysis. Arch Med Sci 2018; 14: 265-75. 